\title{
ELEMENTOS SINTÉTICOS PARA UMA COMPREENSÃO DA CRISE ESTRUTURAL DO CAPITAL
}

\section{Alexandre Aranha Arbia ${ }^{1}$}

\section{Resumo}

Este artigo busca discutir como as três disjunções fundamentais do metabolismo social do capital impelem, no nosso tempo, à instauração de uma crise estrutural permanente que aponta para a dissolução da sociabilidade na barbárie. Busca-se, pois, demonstrar os fundamentos das fissuras, a imanência do desenvolvimento de crises e os pontos de colapso da fase contemporânea do sistema do capital.

Palavras-chave: Crise estrutural do capital; Crises cíclicas; Barbárie.

\section{SYNTHETIC ELEMENTS FOR AN UNDERSTANDING OF THE STRUCTURAL CAPITAL CRISIS}

\begin{abstract}
This article discusses how the three fundamental disjunctions of the capital's social metabolism culminated, in our time, at the installation of a permanent structural crisis that points to the dissolution of sociability into barbarism. Therefore, it seeks to demonstrate the fundamentals of the cracks, the immanent development of the crisis and the break points of the contemporary capital.
\end{abstract}

Keywords: Capital's structural crisis; Cyclical crisis; Barbarism.

\footnotetext{
1 Professor Assistente vinculado ao Departamento de Ciências Sociais, Jornalismo e Serviço Social da Universidade Federal de Ouro Preto (UFOP), doutorando em Serviço Social pela Universidade Federal do Rio de Janeiro (UFRJ), com mestrado e graduação em Serviço Social pela Universidade Federal de Juiz de Fora (UFJF). E-mail: aarbia@gmail.com
} 


\section{ELEMENTOS SINTÉTICOS PARA LA COMPRENSIÓN DE LA CRISIS ESTRUCTURAL DEL CAPITAL}

\section{Resumen}

Este artículo describe cómo las tres disyunciones fundamentales del metabolismo social del capital culminan, en nuestro tiempo, en el establecimiento de una crisis estructural permanente que apunta a la disolución de la sociabilidad en la barbarie. Procura demostrar los fundamentos de las grietas, la inmanencia del desarrollo de las crisis y los puntos de colapso de la fase contemporánea del sistema del capital.

Palabras clave: Crisis estructural del capital; Crisis cíclicas; Barbárie.

\section{Introdução}

Uma das características mais marcantes do sistema do capital é ser cortado por desequilíbrios, contradições e antagonismo. Os problemas são de várias ordens: das disjunções entre os Departamentos I e II, passando pelas ausências de unidade entre produção e controle, produção e circulação e produção e consumo, do antagonismo entre as dinâmicas de funcionamento do micro e do macrocosmo à contradição fundamental do valor, da insuficiência dos mecanismos de controle à explosão do antagonismo entre as classes, toda a dinâmica do capital se mostra um processo de metabolismo social anárquico e incontrolável, exigindo a constituição de um superaparelho corretivo capaz de acionar, em escala macroscópica, mecanismos anticíclicos. Em última instância, as fissuras revelam a separação estrutural entre produção e necessidades humanas e, desta forma, entre os imperativos de expansão e autovalorização do valor e as exigências postas pelo desenvolvimento do gênero humano.

Não poderia ser outro o resultado que não o estabelecimento de uma dinâmica pulsante de aceleração, arrefecimento e depressão, criação acelerada e destruição massiva, anarquia generalizada e incertezas várias em relação à continuidade e à sustentabilidade da produção material. Diferentemente do que acreditavam Bulgakov, Tugan-Baranovski e Hilferding (ROSDOLSKY, 2001, p. 383), o capital global não se subordina a qualquer noção de equilíbrio: "cada período de equilíbrio conduz inevitavelmente a um desequilíbrio, que por sua vez, após certo tempo, torna possível um novo e provisório equilíbrio. Mais ainda, uma das características da economia capitalista é que não apenas as crises, mas também o crescimento acelerado da produção [...] são governados pelas rupturas de equilíbrio" (MANDEL, 1985, p. 17). 


\section{ELEMENTOS SINTÉTICOS PARA UMA COMPREENSÃO DA CRISE \\ ESTRUTURAL DO CAPITAL \\ Alexandre Aranha Arbia}

Tentaremos demonstrar neste artigo as fissuras fundamentais que conferem ao capital uma dinâmica anárquica e explosiva, as linhas-deforça por trás dessas disjunções, a necessidade inarredável de existência de um superaparelho corretivo - o Estado - capaz de mitigar os efeitos das contradições e conter as forças centrífugas, os caracteres gerais que explicam a eclosão das crises cíclicas imanentes e os pontos históricos de saturação que nos colocam na fase da crise estrutural.

\section{As Disjunções Sociometabólicas Fundamentais e o Papel do Estado}

A partir da dificuldade essencial do capital em coordenar as dinâmicas de funcionamento do seu micro e macrocosmo - de suas células individuais e do seu funcionamento enquanto sistema - Mészáros (2002, p. 105) ressalta três disjunções (ou "ausências de unidade") fundamentais em seu sistema sociometabólico: a) a separação radical entre a produção e seu controle; b) a independência da produção em relação ao consumo e c) a falta de articulação entre produção e circulação.

Tratarmos do divórcio entre produção e controle requer considerarmos liminarmente que, enquanto um sistema totalizador, o capital não se submete a qualquer tipo de controle. Ao contrário, constitui-se como "uma forma incontrolável de controle sociometabólico, [...] surgido no curso da história como uma poderosa [...] estrutura 'totalizadora' de controle à qual tudo mais, inclusive seres humanos, deve se ajustar" (MÉSZÁROS, 2002, p. 96, grifos do autor).

A impossibilidade de controle toma a forma de uma anarquia da produção, cuja expressão mais dramática é os ciclos econômicos, que desorganizam não apenas a produção da vida material enquanto esfera econômica específica, mas todo o conjunto da vida cotidiana dos homens. Duas ordens de questões devem ser consideradas aqui.

A primeira delas diz respeito à instauração de uma dinâmica automática do valor - uma autonomização dos movimentos de funcionamento do capital - que se origina na produção (MARX, 2011, p. 580) e toma a forma, na circulação, de um conjunto de relações (materialidades) sociais que submetem os indivíduos, colocando-os em determinadas posições no fluxo das relações sociais. Há, portanto, um vetor que emana da forma pela qual os homens produzem sua existência material para o modo como consolidam essa produção - e o lugar social que ocupam nesse processo. Encontramos, abundantemente, nos escritos marxianos ${ }^{2}$ referências ao estabelecimento de uma dinâmica automática de funcionamento do valor:

\footnotetext{
${ }^{2}$ A questão aparece também no Livro Primeiro de O Capital. Cf. Marx (2006a, p. 437).
} 


\section{ELEMENTOS SINTÉTICOS PARA UMA COMPREENSÃO DA CRISE ESTRUTURAL DO CAPITAL}

Alexandre Aranha Arbia

Se o capital social experimenta uma revolução no valor, pode um capital individual sucumbir e desaparecer por não preencher as condições dessa revolução. Quanto mais agudas e mais frequentes as revoluções do valor, tanto mais o movimento automático do valor como ente autônomo, operando com a força de um fenômeno elementar da natureza, se impõe em confronto com as precisões e os cálculos do capitalista individual [...]. Essas revoluções periódicas confirmam, portanto, o que se quer que elas desmintam: a existência independente que o valor como capital adquire e, com seu movimento, mantém e exacerba (MARX, 2006c, p. 120, grifos nossos).

Noutro ponto, instaura-se, da ótica do capital individual, um paradoxo: a dinâmica de seu processo de trabalho singular aparece como um conjunto de movimentos racionalmente organizáveis e controláveis, ao mesmo tempo em que a realização de seu valor depende de fatores externos, alheios ao seu controle. Neste aspecto, todo o caráter racional toda a possibilidade de controle - revela-se subordinada à anarquia irracional do conjunto. Não por outra razão, constructos teóricos de toda sorte buscam produzir algum tipo de alento subjetivo às microcélulas individuais do sistema: seja pugnando a existência de uma "mão invisível" quase divina, capaz de gerar equilíbrio, passando por todas as formas de aceitação laicas e religiosas da irracionalidade, até, finalmente, a ilusão da possibilidade do controle objetivo total das forças explosivas pelo Estado.

Se a dinâmica de produção do capital torna-se automática (pelo desenvolvimento de uma técnica que inverte a relação sujeito/objeto, entre o ser que trabalha e o instrumento que passa empregá-lo3 ${ }^{3}$, como é possível que os microcosmos da produção submetam-se a processos racionalmente controláveis? A racionalização de tais ambientes só pode significar, pois, o controle hierárquico da força de trabalho manifestando, por uma divisão social e técnica do trabalho, a subordinação real e formal do trabalho pelo capital.

A alienação ${ }^{4}$ do trabalhador em relação ao produto e ao processo o coloca em contradição não apenas com as condições objetivas e subjetivas ${ }^{5}$ de

\footnotetext{
${ }^{3}$ A respeito, cf. o capítulo XIII do Livro Primeiro de O Capital (MARX, 2006a, pp. 425 ss.) e Lukács (1989, p. 97 ss).

${ }^{4}$ A respeito da teoria da alienação de Marx, estudo imprescindível é o de Mészáros (2006). Temos em foco aqui a manifestação do fenômeno exclusivamente no trabalho - em duas de suas dimensões: a alienação do trabalhador em relação ao produto e em relação ao processo -, desconsiderando todas as nuances que abrangem a evolução da teoria marxiana da alienação dos Manuscritos econômico-filosóficos de 1844 aos Rascunhos de 1857-58 (Grundrisse), culminando em sua máxima elaboração em $O$ Capital. O problema serve-nos apenas de passagem para demonstrar a tipicidade da racionalidade que se instaura no interior dos microcosmos da produção. Nossa abordagem, extremamente limitada, não autoriza sua generalização para o conjunto do ser social - as formas de alienação contemporâneas têm caracteres bastante específicos, conformando-se como uma generalização do fetichismo e da reificação por todo o tecido social, como a forma por excelência de positividade da ordem do capital.

5 Para sermos sintéticos: condições objetivas - meios e objetos de trabalho; condições subjetivas - meios de subsistência. Cf. Marx (2011, pp. 372 ss).
} 


\section{ELEMENTOS SINTÉTICOS PARA UMA COMPREENSÃO DA CRISE \\ ESTRUTURAL DO CAPITAL}

Alexandre Aranha Arbia

realização do trabalho, mas em relação a todo o conjunto de mediações com as quais se defronta no interior da produção - o que inclui as personificações do capital e a própria divisão técnica do trabalho. Generalizada, portanto, a alienação do trabalho pelo processo de automatização do capital na produção, qualquer forma de racionalidade no âmbito do microempreendimento só pode manifestar-se como forma de ampliar o controle sobre as ações do trabalhador - pelo adensamento da divisão técnica como exercício efetivo da hierarquia. "O capitalismo necessita sempre de uma hierarquia" (BRAUDEL, 1985, p. 80), e seu funcionamento rígido, inquebrantável, como forma de garantir a subordinação formal e real do trabalho, vertebra todo o sistema do capital como a conditio sine qua non de seu funcionamento.

Assim, não há que se falar, em nenhuma hipótese, na reconciliação entre produção e controle no interior do sistema sociometabólico do capital. A superação de tal contradição supõe a superação da própria estrutura de comando do sistema - da hierarquização estruturada como divisão técnica - e do desaparecimento, no microcosmo, de todas as formas de controle que retiram do trabalhador a autonomia na organização e realização do processo - a luta pela afirmação autônoma do trabalho é, nesse caso e no mesmo golpe, uma luta pela anulação da autonomia do capital, reintroduzindo-a como autonomia do gênero, restabelecendo a autêntica relação sujeito/objeto. A retomada da autonomia exige, também e especialmente, a destruição do Estado em seu papel legislativo e de polícia - indispensável à coordenação e manutenção dos movimentos despóticos do capital no microcosmo da produção.

No que diz respeito à independência produção e o consumo devemos considerar, em primeiro lugar, não se tratar de um divórcio absoluto. Primeiro porque produção é consumo objetivo (de meios de produção) e subjetivo (de força de trabalho essencial) (MARX, 2011, p. 45). Na mesma via, consumo também é produção: o consumo de objetos, meios e força de trabalho culminam na objetivação de um produto (ibid., p. 46). Por outro lado, o consumo produz produção ao realizar (extinguir) o valor-de-uso, requisitando sua reposição. A produção, por seu turno, ao produzir os objetos de consumo, determina o modo pelo qual serão consumidos, criando ainda o impulso para que realizem seus valores-de-uso específicos (MARX, 2011, p. 46-7) ${ }^{6}$.

\footnotetext{
${ }^{6} \mathrm{O}$ que não significa a inexistência de distinção. Devemos lembrar que "essa reciprocidade ativa entre momentos não é uma homogeneização das determinações; moventes e movidos, não por isso, dissolvem suas diferenças, nem mesmo por suas mutações, e também não é desmanchado o gradiente das relevâncias" (CHASIN, 2009, p. 133). A advertência de Lukács, aqui, também é pertinente: "nenhuma interação real [...] existe sem momento predominante. Quando essa relação fundamental não é levada na devida conta, tem-se uma série causal unilateral e, por isso, mecanicista, simplificadora e deformadora dos fenômenos, ou então aquela interação carente de direção, superficialmente rutilante [...]. No caso da interação entre produção e consumo, é evidente que a primeira 'é o ponto de partida efetivo, e, por isso, também o momento predominante'” (LUKÁCS, 2012, p. 334).
} 


\section{ELEMENTOS SINTÉTICOS PARA UMA COMPREENSÃO DA CRISE \\ ESTRUTURAL DO CAPITAL \\ Alexandre Aranha Arbia}

Todavia, a chave para se compreender a independência entre produção e consumo no modo de produção do capital está no grau e na extensão da produtividade capitalista. Por um lado, como em uma típica sociedade mercantil generalizada, a produção não visa a atender as necessidades do produtor imediato: ele não se apodera do valor-de-uso do produto produzido e tampouco é essa a sua finalidade; sua produção visa à troca. Contudo, não se trata de uma mera produção para troca de excedente: trata-se, pelo contrário, de produção de excedente para troca um sistema de trocas que possui um fim em si mesmo e que impulsiona seus próprios mecanismos, elevando a patamares inauditos a produtividade:

O volume da massa de mercadorias produzido pela produção capitalista é estabelecido pela escala dessa produção e pelo imperativo de expansão contínua delas e não por uma órbita predeterminada da oferta e da procura, das necessidades a satisfazer. A produção em massa só pode ter por comprador imediato, além de outro capitalista industrial, o comerciante por atacado. Até certo ponto, pode dar-se ao processo de reprodução na mesma escala ou em escala ampliada, embora as mercadorias dele oriundas não entrem realmente no consumo individual ou produtivo (MARX, 2006c, p. 86).

A independência entre produção e consumo é um dos elementos mais significativos $^{7}$ na explicação das crises de superprodução de valores de troca:

[com a constituição intermediária do comerciante de atacado] pode aumentar a produção de mais-valor e [...] encontrar-se em pleno progresso todo o processo de produção, e, apesar disso, grande parte das mercadorias ter entrado na esfera da circulação apenas na aparência, continuando na realidade armazenada nas mãos dos revendedores sem ser vendida,

\footnotetext{
${ }^{7}$ Mas não o único. Não há dúvida de que nesta disjunção podemos encontrar o fundamento último das crises de superprodução. Contudo, o desenvolvimento do capital monopolista - sob a rubrica das sociedades anônimas e do capital financeiro (que tende crescer exponencialmente a cada crise cíclica) - coloca dimensões novas e incontornáveis para a compreensão da peculiaridade das crises em nosso tempo (temos em mente aqui, especialmente, os ciclos curtos). Analisando os cadernos marxianos de 1868/1869 e seu lugar heurístico no processo de construção do Livro Terceiro de O Capital, PAULA et al. $(2015, p$. 8) demonstram que "in a crisis, credit works in order to guarantee that money functions primarily as money-capital, guaranteeing that part of the capitalist class has access to a major portion of all social savings. In this scenario, the profit rate has nothing to do with the level of interest. However, what Marx names 'pressure for pecuniary accommodation' does not concern capital itself, but only banking capital, no matter of what kind. State papers, securities, bank notes, and mortgages appear here only as moneycapital and, especially, as titles over capital itself: 'This is very important; that such pressure on banking capital and its relative scarcity in respect to the demand for it is confused with a diminution of real capital that in such cases overstocks the markets.' This causes a decrease in the banking capital that is transformed again into money and the capital available in society is turned into money capital, until its transformation into world money, with the decrease in national reserves of gold. During a crisis, after all, banks fear a drain of gold above everything else. Periods of crisis increase the demand not for capital, but for money itself, which is evident from the fact that crises exhibit an overstock of capital in all its forms".
} 


\section{ELEMENTOS SINTÉTICOS PARA UMA COMPREENSÃO DA CRISE ESTRUTURAL DO CAPITAL \\ Alexandre Aranha Arbia}

retida, portanto, no mercado. Uma remessa de mercadoria sucede a outra, para se verificar no fim que a remessa anterior apenas aparentemente foi absorvida. Os capitais-mercadorias disputam entre si um lugar no mercado. Os retardatários, para vender, vendem abaixo do preço. As remessas anteriores de mercadorias não foram ainda liquidadas, mas já venceram os prazos de pagá-las. Quem detém as mercadorias invendáveis tem de declarar-se insolvente ou vendê-las a qualquer preço, para pagá-las. Essa venda nada tem a ver com a verdadeira situação da procura. Está apenas relacionada com a procura de meios de pagamento, com a necessidade absoluta de converter mercadoria em dinheiro. Estala [sic] então a crise. Torna-se visível [...] na diminuição da troca entre capitais, do processo de reprodução do capital (MARX, 2006c, p. 87).

$\mathrm{Na}$ contemporaneidade, encontramos estirada ao limite a subordinação do valor-de-uso ao valor de troca. Reunificar produção e consumo supõe inverter exatamente esse processo: a superação do antagonismo entre valor-de-uso e valor de troca só pode ser resolvida historicamente com a supressão absoluta do valor, ou seja, com a realização de uma produção que, voltada exclusivamente à produção de valores-de-uso, possa conciliar desenvolvimento material e realização do gênero - algo impensável no interior da dinâmica do capital, afinal, é ele a única medida de si mesmo. Neste aspecto, cabe ao Estado não apenas criar mecanismos que facilitem a conexão produção/consumo, removendo possíveis obstáculos à aceleração do tempo de rotação, como assumir a função de comprador/consumidor direto em escala crescente, seja provendo necessidades reais (como educação, saúde, habitação, etc.), seja mantendo apetites artificiais (como o aparelho burocrático-administrativo, e, especialmente, o complexo militar-industrial).

Por fim, com relação à desarticulação entre produção e circulação, devemos considerar, como vimos, que a hipertrofia da circulação é uma exigência posta pelas próprias características imanentes da produtividade do capital. Primeiro, porque a realização do mais-valor depende fundamentalmente de condições externas ao processo de produção (a realização do ciclo de rotação, o tempo de sua duração, constitui a soma dos tempos de produção e do tempo de circulação). A típica racionalização capitalista (hierarquia fundada na divisão técnica) espalhase para o conjunto da circulação, pelos setores intermediários, como forma de constituição de empreendimentos capitalisticamente viáveis exploração técnico-racional, em todas as suas minúcias, da força de trabalho empregada nesses setores.

A organização racional da circulação - cuja prioridade é a obtenção de lucro pelos empreendimentos individuais nela operantes - promove, pelo mesmo ato, uma aceleração no tempo de rotação dos capitais-mercadoria. Aqui, temos algumas consequências bastante peculiares. A racionalização faz com que os setores intermediários se ampliem e diversifiquem, 


\section{ELEMENTOS SINTÉTICOS PARA UMA COMPREENSÃO DA CRISE ESTRUTURAL DO CAPITAL \\ Alexandre Aranha Arbia}

acelerando o tempo de rotação do capital-mercadoria, mas, por outro lado, aumentam a massa de capital improdutivo - uma exigência de sua expansão - a dragar valor da massa total do capital social. Por fim, a constituição do comércio por atacado faz com que a metamorfose final $\mathrm{M}^{\prime}$ - D' deixe de significar consumo imediato. Se, num primeiro momento, esse fator favorece o capital industrial - que pode se realizar vendendo grande quantidade de produtos de uma só vez - ele não resolve o problema da ausência de unidade entre produção e consumo, consistindo no prelúdio de manifestação das crises de superprodução.

O problema da superprodução tem como contraface o subconsumo. Ou seja, a superprodução é, de resto, um fenômeno relativo: refere-se ao sobreacúmulo de valores de troca em relação à capacidade de sua realização. Tal sobreacúmulo (que implica a não realização do valor-deuso) não ocorre de forma indiferenciada ou geral - vincula-se à inexistência, num dado momento do processo de acumulação, de demanda solvável. A destruição de gigantescas massas de capitaismercadoria (e, algumas vezes, de capital produtivo) toma, à primeira vista, a forma de uma irracionalidade inexplicável.

Como justificar, por exemplo, o descarte de toneladas de alimentos frente à expansão flagrante da fome pelo mundo? Conforme Braudel (1985, p. 93) e Chesnais (1996, p. 38-9), o capital tende a formação de centros, em torno dos quais articula seu processo de acumulação: centros de produção, circulação e consumo, cuja constituição pressupõe a formação de periferias. As crises de superprodução explicam-se pela incapacidade de realização do ciclo do capital dentro do conjunto de pontos integrados do sistema. Não basta, pois, a simples existência de demanda por valores-de-uso: é imperativo que haja capacidade de realização do valor - que se realize a metamorfose $\mathrm{M}^{\prime}$ - $\mathrm{D}^{\prime}$. Essa é a condição obrigatória para que os valores-de-uso se realizem. A integração de alguns pontos (nações) periféricos (para falarmos apenas da periferia integrada) é reduzida, no mais das vezes, ao fornecimento de matériasprimas ou, o mais grave, à produção de capitais-mercadorias que terminam por não realizar, nesses países, o ciclo global do capital. O resultado é uma desertificação onde a circulação não se conclui, culminando na escassez em meio à abundância da produtividade global do capital.

Neste processo, o Estado é chamado a atuar facilitando, regulamentando (ou até mesmo criando) a circulação dentro de seu sistema de Estado nação, favorecendo o intercâmbio globalizado, legitimando a ordem mundial internacional e nacionalmente, assegurando "a coleta regular dos superlucros do monopólio no exterior, como [garantindo] as condições de acumulação regular do capital em sua pátria" (MANDEL, 1985, p. 220). Extinguir a produção da escassez requer priorizar as demandas humano-genéricas, em detrimento dos imperativos autoexpansivos do capital, rompendo com uma circulação que obedece 


\title{
ELEMENTOS SINTÉTICOS PARA UMA COMPREENSÃO DA CRISE \\ ESTRUTURAL DO CAPITAL \\ Alexandre Aranha Arbia
}

exclusivamente a lógica do valor e a uma distribuição ordenada pelo lucro.

Não há, pois, que se falar em redução do Estado na fase de crise estrutural do capital. Pelo contrário, é imperativo que ele explicite agora, com força inaudita, sua função ontológico-estrutural, a fim de retificar a falta de unidade em todos os três aspectos referidos, retardando o colapso:

\begin{abstract}
o Estado capitalista precisa agora assumir um papel intervencionista direto em todos os planos da vida social, promovendo e dirigindo ativamente o consumo destrutivo e a dissipação da riqueza social em escala monumental. Sem esta intervenção direta no processo sociometabólico, que age não mais apenas em situações de emergência mas em base contínua, torna-se impossível manter em funcionamento a extrema perdularidade do sistema capitalista contemporâneo (MÉSZÁROS, 2002, p. 700).
\end{abstract}

Exacerbados os limites, aflora o dilema de morte para o sistema do capital: incapaz de conter as forças centrífugas que prenunciam o colapso, depende, cada vez mais, para sua continuidade, de uma capacidade crescente de articulação, coordenação de administração dos pontos de estrangulamento - mas essa é exatamente a necessidade de imposição de controle ao qual o capital não se pode submeter. Emperrado em seu processo de acumulação, deve livrar-se das limitações que restringem sua autoexpansão, ao mesmo tempo em que encontra, nessas limitações, os liames mínimos de integração de seu sociometabolismo anárquico. Não por outra razão, o Estado é ontologicamente indispensável e (ao mesmo tempo) deletério para assegurar a plena fluidez do sistema do capital, ao mesmo tempo em que se tornou, social e historicamente, simplesmente impotente para conter as forças centrífugas que consolidam a instauração da barbárie.

\section{Das Crises Cíclicas aos Pontos de Gargalo da Crise Estrutural}

O processo cíclico de crises é imanente e estrutural à dinâmica do capital. Pode se consolidar na forma de crises gerais, envolvendo um colapso generalizado das relações econômicas, ou crises parciais que, encerrando os ciclos econômicos, constituem uma constante regular (e restauradora) no modo de produção do capital. Nas crises, ocorre a destruição dos capitais mais fracos, sua absorção por grandes massas de capital e a retomada de um relativo equilíbrio (temporário) entre produção e consumo. As crises são uma saída do próprio sistema para desobstruir o ciclo de realização, retornando o processo de expansão do capital a uma regularidade instável (MARX, 2006c, p. 209).

A abordagem dos elementos mais gerais que levam a eclosão de crises exige-nos uma advertência: embora não encontremos em Marx uma 


\section{ELEMENTOS SINTÉTICOS PARA UMA COMPREENSÃO DA CRISE ESTRUTURAL DO CAPITAL}

"teoria das crises", podemos buscar em suas elaborações os elementos mais abstratos, presentes na maior parte das crises econômicas ${ }^{8}$, sem perder de vista que cada crise é uma crise particular, explicada por seus caracteres específicos: "cada crise de superprodução combina traços gerais, que dizem respeito às contradições fundamentais do modo de produção capitalista, com traços particulares que resultam do momento histórico preciso no qual ela se produz no curso do desenvolvimento desse modo de produção" (MANDEL, 1985, p. 28). Feita a advertência, podemos seguir Mandel (1990, p. 214) na observação das tendências mais gerais.

A partir de um dado momento na conjuntura de crescimento, observase um inegável aumento da composição orgânica do capital. Por um curto período, ainda é possível manter uma taxa de lucro elevada, especialmente se se consegue aumentar a taxa de mais-valor valendo-se do retardo no reajuste do preço das matérias-primas. Mas o alcance do superlucro tende a se tornar progressivamente mais difícil; duas são as dificuldades: segurar os salários, considerada a retração do exército industrial de reserva pela expansão da produção e o aumento do emprego, e manter o preço das matérias-primas, que, com o prolongamento do período de expansão, tendem a escassez.

A duração da expansão imanta e retém o capital em seu conjunto em torno das economias com maiores taxas de desenvolvimento e acumulação, dificultando o escoamento dos capitais excedentes para países ou setores onde haja uma baixa composição orgânica. A enxurrada de mercadorias não encontra meios para sua realização, uma vez que a produção não se direciona pela necessidade. Uma massa considerável de capitais passa a encontrar cada vez maiores dificuldades de valorização em meio à superacumulação.

Os mercados centrais tornam-se abarrotados, enquanto a escassez prolifera pela periferia do sistema. Os círculos de consumo não encontram meios de expansão - instaura-se uma prática agressiva que busca reduzir o tempo de rotação do consumo, insuflando a perdularidade que estira a produção predatória e destrutiva ao limite. As mercadorias encalham e a produção do desemprego, agora impulsionada pela própria exigência de aumento da composição orgânica e da realização do lucro, ganha face dramática, com a diminuição forçada da capacidade produtiva. A obliteração das vias do capital produtivo leva todo o sistema a depender de forma crescente e decisiva, para a manutenção de seu funcionamento,

\footnotetext{
${ }^{8}$ Marx aludia a ciclos econômicos - em sua época, decenais - a partir dos quais era possível perceber a escalada da acumulação rumo às crises. A respeito e com as cautelas de estilo, evitando cristalizar as etapas em um método apriorístico e anistórico, oferece a seguinte explicação: "O curso característico da indústria moderna, um ciclo decenal, com a intercorrência de movimentos oscilatórios menores, constituído de fases de atividade média, de produção a todo vapor, de crise e de estagnação, baseia-se na formação contínua, na maior ou menor absorção e na reconstituição do exército industrial de reserva, a população supérflua excedente" (MARX, 2006b, p. 736) e ainda de forma assertiva: “Desde já está claro que, em virtude desse ciclo de rotações conexas, que abarca uma série de anos e no qual o capital está preso por sua parte fixa, forma-se uma base material das crises periódica em que os negócios passam por fases sucessivas de depressão, animação média, auge, crise" (MARX, 2006c, p. 209).
} 


\section{ELEMENTOS SINTÉTICOS PARA UMA COMPREENSÃO DA CRISE \\ ESTRUTURAL DO CAPITAL}

Alexandre Aranha Arbia

das linhas de crédito do capital financeiro, seja para garantir o consumo produtivo $^{9}$ (o que implicará elevação da fatia destinada aos juros no montante global do mais-valor social), seja para garantir o consumo improdutivo (através do crédito privado a famílias de trabalhadores, instaurando como prática em larga escala a troca de mercadorias por rendimentos futuros ${ }^{10}$ ). Os capitais mais fracos são finalmente sorvidos pelas grandes massas de capital - revela-se outra tendência inescapável do capital: a formação de monopólios.

Colocados os determinantes, um detonador - que jamais é a causa da própria crise (MANDEL, 1990, p. 212) - acaba por impulsionar a reação em cadeia, prenunciando um período de quebras, falências, demissões em massa, retração da produção e do comércio - está instalada a crise. Sucede a estagnação da produção, na qual os salários permanecem rebaixados e as mercadorias acumuladas - a busca desesperada pelas vendas não exclui ações de destruição física de capitais-mercadoria. Tem início um processo de rearranjo econômico, com busca por soluções técnicas (e tecnológicas), abertura de mercados e fusões - é a fase da depressão. A destruição da massa de capitais, o reordenamento do mercado e as incorporações técnicas (e tecnológicas) possibilitam, lentamente, uma retomada da produção e da acumulação: é o início de um novo período expansivo, que leva ao crescimento da produção, acumulação de capital e prosperidade.

Vistos os elementos, cabe-nos agora perguntar se os condicionantes postos pela atual fase do capital permitem realizar algum tipo de retomada e qual a atualidade da explicação oferecida pela teoria das crises cíclicas.

Hoje, as crises cíclicas foram dragadas por uma extensa espiral descendente. Os ciclos se manifestam agora em depressões bastante agudas, de difícil recuperação, em uma flagrante incapacidade de retomada das taxas de lucro em padrões aceitáveis. Como ponto de inflexão, as dificuldades estruturais do sistema em resolver o leque de contradições explosivas que se exacerbam pós-1970.

Em primeiro lugar, trata-se de uma crise de caráter universal, que não se restringe a qualquer esfera econômica particular. Também se mostra como uma crise institucional, atingindo todas as formas sociais: do Estado à família, da cultura à economia - é completamente inegável a incapacidade das mediações de segunda ordem de assegurarem soluções estáveis, fazendo refluir as forças centrífugas. Como um processo generalizado, apresenta-se como crise de um modo histórico de sociabilidade: o sociometabolismo do capital. Seu alcance global não a

\footnotetext{
${ }^{9}$ Assim expressa Mandel (1990, p. 215): “de um lado, a queda da taxa média de lucros deve desencadear, nas condições de prosseguimento da expansão e de aprofundamento da especulação, o recurso incessantemente crescente ao crédito e, portanto, um agravamento do endividamento das empresas. [...] A expansão acelerada do crédito é praticamente inevitável, uma vez que os bancos se esforçam por evitar as bancarrotas em cadeia que lhes causariam graves perdas".

${ }^{10}$ Cf. Mandel (1985, p. 280-1).
} 


\title{
ELEMENTOS SINTÉTICOS PARA UMA COMPREENSÃO DA CRISE \\ ESTRUTURAL DO CAPITAL \\ Alexandre Aranha Arbia
}

restringe a apenas alguns países: como um moinho irresistível, arrasta para a barbárie todos os cantos do globo, do centro à periferia integrada $\mathrm{e}$ desta às nações marginais, revelando, de forma dramática, a completa integração global do sistema do capital.

Sob a forma de um continuum depressivo, suprassumiu os ciclos curtos, revertendo a fase ascendente do capital (1945-1968) em uma crise permanente. Primeiro, pela obliteração histórica das possibilidades de saída tradicionais: a expansão geográfica e a guerra mundial. Segundo pelo próprio esgotamento da dinâmica do valor: beco sem saída posto pela revolução tecnológica pós-1970, que expulsou, num movimento inaudito e sem retorno, massas gigantescas de força viva de trabalho da produção material.

Por fim, conforma-se como uma crise "rastejante" por não se anunciar como um colapso global catastrófico, um "dia do Juízo Final" (MÉSZÁROS, 2002, p. 799) - embora tal possibilidade não possa ser excluída -, mas como um caminho acelerado e permanente em direção à barbárie. Na síntese de Mészáros,

\begin{abstract}
A crise estrutural do capital que começamos a experimentar nos anos 70 se relaciona, na realidade, a algo muito mais modesto que tais condições absolutas. Significa simplesmente que a tripla dimensão interna da autoexpansão do capital exibe perturbações cada vez maiores. Ela não apenas tende a romper o processo normal de crescimento mas também pressagia uma falha na sua função vital de deslocar as contradições acumuladas do sistema (MÉSZÁROS, 2002, p. 799).
\end{abstract}

Os elementos da decadência do metabolismo social do capital são cada vez menos ignoráveis, revelando-se em pontos muito salientes.

Os padrões de produtividade do capital articulados à taxa de uso decrescente $^{11}$ só podem culminar em desmedida e irracionalidade no intercâmbio homem/natureza, convertendo as potencialidades da emancipação genérica em relação ao ser natural em exploração predatória, ameaçando esgotar os recursos mais significativos que sustêm ontologicamente o ser social. Isso porque todas as preocupações se encerram na realização do ciclo de valorização: desde que a metamorfose (produtiva) se realize lucrativamente (possibilite a criação do mais-valor), não importa o quão perdulária e predatória ela seja. Por outro lado, o encerramento do ciclo de realização na metamorfose $M^{\prime}$ - $D^{\prime}$ desresponsabiliza o capital do destino final do capital-mercadoria: uma

${ }^{11}$ Assim expressa Mészáros a respeito da taxa de uso decrescente: "o que é verdadeiramente vantajoso para a expansão do capital não é um incremento na taxa (ou no grau) com que uma mercadoria [...] é utilizada, e sim pelo contrário, o decréscimo de suas horas de uso diário. Enquanto tal decréscimo for acompanhado por uma expansão adequada do poder aquisitivo da sociedade, cria-se a demanda por outra [mercadoria]" (MÉSZÁROS, 2002, p. 661). 


\section{ELEMENTOS SINTÉTICOS PARA UMA COMPREENSÃO DA CRISE \\ ESTRUTURAL DO CAPITAL \\ Alexandre Aranha Arbia}

vez realizada a metamorfose e encerrado o ciclo, o destino do produto é indiferente.

A escassez dos recursos naturais e a invasão sem precedentes do setor de commodities pelo capital financeiro prenunciam uma das faces mais bárbaras da fase hipertardia do capital em decomposição: a explosão da fome. Conforme Ziegler (2013, p. 291), entre 2003 e 2008 as especulações sobre matérias-primas aumentaram em $2.300 \%$. Relatórios da FAO mostram que apenas $2 \%$ dos contratos futuros referentes a matériasprimas, em 2011, foram concluídos efetivamente com entrega de mercadorias: 98\% foram revendidos pelos especuladores antes da data de conclusão, e, segundo as estimativas do Banco Mundial, 44 milhões de homens, mulheres e crianças das classes vulneráveis dos países de baixa renda juntaram-se ao exército dos subalimentados e/ou atingidos pela fome, exatamente pós-2011 (ZIEGLER, 2013, p. 289).

A desertificação provocada pelo capital nas periferias tem acirrado conflitos internos, provocando um tsunami humano de refugiados que se espalha por todo o mundo. Constituídos como massa de população sobrante, vivenciaram a implosão sistêmica de suas nações, processo que as tirou da condição de

\footnotetext{
países subordinados, reservas de matérias-primas, sofrendo os efeitos conjuntos da dominação política e do intercâmbio desigual, como na época 'clássica' do imperialismo, [para se tornarem] países que praticamente não mais apresentam interesse, nem econômico, nem estratégico (fim da "guerra fria") para os países e companhias que estão no centro do oligopólio. [Verdadeiros] [...] pesos mortos, pura e simplesmente. [...] [Constituíram-se em extensas] [...] áreas de "pobreza" [...], cujos emigrantes ameaçam os "países democráticos" (CHESNAIS, 1996, p. 39).
}

Fomentar conflitos locais tem sido uma das válvulas de escape para a superprodução do complexo millitar-industrial. Órfão de conflitos em escala planetária, enfrenta um paradoxo: ao mesmo tempo em que aumenta o alcance e o refinamento do potencial destrutivo de sua produção, tem seu uso em larga escala inviabilizado exatamente por seu altíssimo potencial catastrófico. Noutra ponta, o elevado desenvolvimento técnico de sua produção tem sido usado substancial e regularmente pelos Estados nacionais centrais como mecanismos de controle administrativo e submissão coercitiva, tornando o "estado de exceção" uma realidade permanente.

O processo de "periferização dos centros" agudiza o problema no interior dos Estados centrais. Incapazes de oferecer soluções estruturais pelos limites do próprio capital em colapso - revelam suas falências nas ações paliativas inócuas. De uma parte, ampliam a coerção, restringindo a circulação das populações sobrantes; por outra, são estruturalmente 


\section{ELEMENTOS SINTÉTICOS PARA UMA COMPREENSÃO DA CRISE \\ ESTRUTURAL DO CAPITAL \\ Alexandre Aranha Arbia}

incapazes de assumir a reprodução dessas populações sem se desviarem das ações prioritárias para o capital em crise - como a alimentação do capital financeiro.

Em seu calvário rumo à barbárie, aturdidos por um pressentimento surdo da dissolução da única forma de vida que conhecem, os homens vêm aderindo a particularismos de todo o tipo, desde o recrudescimento dos movimentos xenófobos ao acirramento dos conflitos étnicos, geracionais e de gênero. A retração dos mercados de trabalho - imposta pela irreversível revolução técnico-industrial do último terço do séc. passado, que explodiu as faixas do desemprego estrutural - confrontou os indivíduos com a impossibilidade de manter suas próprias autorreproduções dentro dos padrões estabelecidos pelo capital. Fortalecidas pela expansão de uma ideologia irracionalista, as saídas particularistas ganham corpo extensivo, aumentando seu número de adeptos na mesma proporção em que produzem soluções cada vez mais violentas e unilaterais.

Por derradeiro, os pontos de gargalo da crise estrutural do capital revelam a falência miserável dos Estados nacionais em continuar cumprindo suas funções de coordenadores e controladores do sistema global do capital. Enfrentam a contradição da exigência de atuação em escala internacional ao mesmo tempo em que precisam conviver prosaicamente com interesses particulares e chauvinistas, que impedem a constituição de um Estado universal.

Para os grandes trustes, funcionam como organismos de pressão política e coerção militar na desregulamentação institucional e legal de países periféricos, na desestabilização social e política de governos e no desmonte de potenciais relações explosivas que venham a comprometer a produção, a extração e a repatriação dos lucros que obtém nesses países. Por outro lado, a organização policêntrica do capital (EUA, Alemanha e China), coloca os Estados nacionais em posição de potencial conflito de interesses, especialmente sob a pressão das gigantescas massas de capital que não encontram meios de manter, em patamares compatíveis às exigências de suas próprias magnitudes, a produção de excedente. Nesses moldes, as consequências são totalmente imprevisíveis.

\section{Referências}

BRAUDEL, Fernand. A Dinâmica do Capitalismo. Coleção Teorema Breve.Trad. Carlos da Veiga Ferreira. Lisboa: Teorema, 1985.

CHASIN, José. Estatuto ontológico e resolução metodológica. São Paulo: Boitempo, 2009.

CHESNAIS, François. A mundialização do capital. Trad. Silvana Finzi Foá. São Paulo: Xamã, 1996. 


\section{ELEMENTOS SINTÉTICOS PARA UMA COMPREENSÃO DA CRISE \\ ESTRUTURAL DO CAPITAL}

Alexandre Aranha Arbia

LUKÁCS, György. Para uma ontologia do ser social I. Trad. Carlos Nelson Coutinho, Mário Duayer e Nélio Schneider. São Paulo: Boitempo, 2012.

História e consciência de classe. Estudos de dialética marxista. Rio de Janeiro/Porto: Elfos/Escorpião, 1989.

MARX, Karl. Grundrisse. Manuscritos econômicos de 1857-1858. Esboços da crítica da economia política. Trad. Mário Duayer e Nélio Schneider. São Paulo: Boitempo, 2011.

O Capital. Livro Primeiro. O processo de produção do capital. Vol. 1. 24. Ed. Trad. Reginaldo Sant'Anna. Rio de Janeiro: Civilização Brasileira, 2006a.

O Capital. Livro Primeiro. O processo de produção do capital. Vol. 2. 21. Ed. Trad. Reginaldo Sant'Anna. Rio de Janeiro: Civilização Brasileira, 2006b.

O Capital. Livro Segundo. O processo de circulação do capital. 11. Ed. Trad. Reginaldo Sant'Anna. Rio de Janeiro: Civilização Brasileira, 2006c.

MANDEL, Ernest. A crise do capital. Os fatos e sua interpretação marxista. Trad. Juarez Guimarães e João Machado Borges. São Paulo/Campinas: Ensaio/Unicamp, 1990.

O Capitalismo Tardio. Coleção Os Economistas. 2. ed. São Paulo: Abril Cultural, 1985.

MÉSZÁROS, István. A teoria da alienação em Marx. Tradução de Isa Tavares. São Paulo: Boitempo, 2006.

Para além do capital. Tradução de Paulo César Castanheira e Sérgio Lessa. São Paulo: Boitempo, 2002.

PAULA, João Antônio de; CERQUEIRA, Hugo Eduardo da Gama; DEUS, Leonardo Gomes de; SUPRINYAK, Carlos Eduardo; ALBURQUERQUE, Eduardo da Motta. Marx, the Notebooks on the crisis of 1866 and structural changes in capitalism: Investigating Financial Innovation and Stock Exchanges. Disponível em http:/ / www.cedeplar.ufmg.br/component/content/article/191-textospara-discussao/1654-marx-the-notebooks-on-the-crisis-of-1866-and- 


\section{ELEMENTOS SINTÉTICOS PARA UMA COMPREENSÃO DA CRISE \\ ESTRUTURAL DO CAPITAL}

Alexandre Aranha Arbia

structural-changes-in-capitalisminvestigating-financial-innovation-andstock-exchanges.html. Acesso em 10 out.2015.

ROSDOLSKY, Roman. Gênese e Estrutura de O Capital de Karl Marx. Trad. César Benjamin. Rio de Janeiro: UERJ/Contraponto, 2001.

ZIEGLER, Jean. Destruição em massa. Geopolítica da fome. Trad. José Paulo Netto. São Paulo: Cortez, 2013. 